\title{
Pharmacogenomics and COVID-19: clinical implications of human genome interactions with repurposed drugs
}

\author{
Osama A. Badary (D) $^{1,2}$
}

Received: 13 June 2020 / Revised: 7 December 2020 / Accepted: 15 January 2021 / Published online: 4 February 2021

(c) The Author(s), under exclusive licence to Springer Nature Limited 2021

\begin{abstract}
The outbreak of Coronavirus disease 2019 (COVID-19) has evolved into an emergent global pandemic. Many drugs without established efficacy are being used to treat COVID-19 patients either as an offlabel/compassionate use or as a clinical trial. Although drug repurposing is an attractive approach with reduced time and cost, there is a need to make predictions on success before the start of therapy. For the optimum use of these repurposed drugs, many factors should be considered such as drug-gene or dug-drug interactions, drug toxicity, and patient co-morbidity. There is limited data on the pharmacogenomics of these agents and this may constitute an obstacle for successful COVID-19 therapy. This article reviewed the available human genome interactions with some promising repurposed drugs for COVID-19 management. These drugs include chloroquine (CQ), hydroxychloroquine (HCQ), azithromycin, lopinavir/ritonavir (LPV/r), atazanavir (ATV), favipiravir (FVP), nevirapine (NVP), efavirenz (EFV), oseltamivir, remdesivir, anakinra, tocilizumab (TCZ), eculizumab, heme oxygenase 1 (HO-1) regulators, renin-angiotensin-aldosterone system (RAAS) inhibitors, ivermectin, and nitazoxanide. Drug-gene variant pairs that may alter the therapeutic outcomes in COVID-19 patients are presented. The major drug variant pairs that associated with variations in clinical efficacy include $\mathrm{CQ} / \mathrm{HCQ}(C Y P 2 C 8, C Y P 2 D 6, A C E 2$, and HO-1); azithromycin (ABCB1); LPV/r (SLCO1B1, ABCB1, ABCC2 and CYP3A); NVP (ABCC10); oseltamivir (CES1 and ABCB1); remdesivir (CYP2C8, CYP2D6, CYP3A4, and OATP1B1); anakinra (IL-1a); and TCZ (IL6R and FCGR3A). The major drug variant pairs that associated with variations in adverse effects include CQ/HCQ (G6PD; hemolysis and $A B C A 4$; retinopathy), ATV (MDRI and UGTIAI*28; hyperbilirubinemia; and APOA5; dyslipidemia), NVP (HLA-DRBI*01, HLA$B * 3505$ and CYP2B6; skin rash and MDRI; hepatotoxicity), and EFV (CYP2B6; depression and suicidal tendencies).
\end{abstract}

\section{COVID-19}

\section{COVID-19 background}

The new pandemic coronavirus disease 2019 (COVID-19) is caused by the novel Severe Acute Respiratory Syndrome coronavirus 2 (SARS-CoV-2). COVID-19 is currently triggering enormous global demands on health systems and presents an unprecedented challenge to identify effective drugs for prevention and treatment [1]. Coronaviruses have

Osama A. Badary

osama.badary@bue.edu.eg

1 Clinical Pharmacy Practice Department, Faculty of Pharmacy, The British University in Egypt (BUE), Cairo, Egypt

2 Clinical Pharmacy Department, Faculty of Pharmacy, Ain Shams University, Cairo, Egypt a genome made of RNA. Viruses with RNA genomes have an essential gene called the RNA-dependent RNA polymerase (RdRp), which is highly conserved, meaning that there are few changes in the gene from one RNA virus to another [2]. SARS-CoV2 binds principally to the cell-membrane angiotensen converting enzyme 2 (ACE2) receptors through the viral structural spike (S) protein [3]. At the intracellular level, the virus activates cellular processes to produce viral proteins that replicate the virus's genetic material, providing potential targets for drug therapy [4].

\section{COVID-19 therapy}

In an urgent attempt to mitigate devastating catastrophe of SARS-CoV2, many drugs without established efficacy have been used in patients either as an offlabel/compassionate use or as a clinical trial [5-8]. A combination of antivirals with different mechanisms of action may be more effective but at 
the same time, their adverse effects should not be underestimated $[9,10]$. Mechanistic and in vitro analyses suggest multiple promising therapeutic options with potential for repurposing to treat patients with COVID-19 [11]. Drug repurposing is an attractive approach with reduced time and cost to treat COVID-19 [12-14]; however, limitations such as low success rate and the possibility of adverse side effects, can not be overlooked [13-17]. There is limited data on the human genome interactions with many of these agents and this may constitute an obstacle for successful COVID-19 therapy. Knowing the major human genetic variants association with the clinical therapeutic outcome has the potential not only to expedite emergency use authorization and approvals but also to afford an additional level of safety and efficacy to patients. Therefore, the purpose of this review is to look at some drugs commonly used in regimens for COVID-19 and provides specific examples of how genetics may affect drug efficacy and toxicity. It adds to the efforts of recently published relevant articles [18-20] and does not serve as an exhaustive review of all relationships between host genetics and these drugs.

\section{Pharmacogenomics (PGx) overview}

\section{Genetic polymorphism}

Genetic polymorphisms are a type of genetic diversity within a population's gene pool. Single nucleotide polymorphisms (SNPs), are the most common type of genetic variation among people. Various polymorphisms exist in genes encoding phase 1 cytochrome P450 (CYP) or phase 2 drug-metabolizing enzymes, transporters, drug targets, or human leucocyte antigen (HLA) alleles and predict drug efficacy or toxicity [21, 22]. Genetic variations of CYP2C9, CYP2D6, CYP2C19 and CYP3A5 were associated with therapeutic effects of phenytoin [23], tamoxifen [24], clopidogrel [25], and tacrolimus [26], respectively. The dose regimens of mercaptopurines and irinotecan should be adjusted according to the polymorphism of thiopurine methytransferase (TPMT) [27] and UDP glucuronosyltransferase 1A1 (UGT1A1) [28], respectively. A variant allele in the solute carrier organic anion transporter family member 1B1 (SLCO1B1) gene has been associated with statin-induced myalgia [29]. A common variant in the vitamin $\mathrm{K}$ epoxide reductase complex subunit 1(VKORC1) gene, has also been strongly associated with inter-individual warfarin dosing variability [29].

\section{Pharmacogenetics and PGx}

The genetic polymorphisms constitute the basis of pharmacogenetics which means the monogenic variants which alter the drug response [30]. The term pharmacogenetics was coined in 1957 [31]. On the other hand, PGx is the genome-wide analysis of genetic determinants of drug metabolizing enzymes, receptors, transporters, and targets that influence therapeutic efficacy and safety [32]. The realization that most variable drug responses appear to be multifactorial led to the rise of interest in PGx, a rise paralleled by the expansion of genetics into genomics.

\section{Evidence-based PGx resources}

The rapid innovation in sequencing technology and genome-wide association studies has led to the development of numerous data resources and dramatically changed the landscape of PGx research. Resources provided by organizations such as The Clinical Pharmacogenetics Implementation Consortium (CPIC) [27] and The PGx Knowledgebase (PharmGKB) [33], that use standardized approaches to evaluate the literature and provide clinical guidance, are essential for the implementation of pharmacogenetics into routine clinical practice. Important online resources such as PharmGKB.org and cpicpgx.org provide the clinician with summarized PGx associations and clinical guidelines. Other resources include SCAN and PACdb PGx databases developed and published by the PGx of Anticancer Agents Research Group. SCAN is designed to collect, annotate, and present the relationship between genotype and gene expression. It is a large-scale genetic and genomic database containing SNP and copy number variation annotations along with a web interface, a set of methods and algorithms, and some data mining tools [34]. $\mathrm{PACdb}$ is a pharmacogenetics-cell line database collecting pharmacology-related information including genotypes, gene expression, and pharmacological data gathered via lymphoblastoid cell lines [35].

\section{PGx clinical implications and testing}

In recent years, clinical evidence has strengthened, guidelines have emerged, and genomic medicine is becoming integrated into routine care for certain disease states, such as some cancers. Recently, the FDA approved direct-toconsumer tests for PGx, breast cancer risk, and propensity to develop certain conditions (e.g., Parkinson's and Alzheimer's diseases) [36]. A notable example is that CYP2C9 and VKORC1 genotypes predict different sensitivity and resistance frequencies in the Ashkenazi and Sephardi Jewish populations necessitating warfarin dose adjustment [37]. Many major medical institutions have started implementing genotyping protocols for preemptive pharmacogenetic testing [38]. A good example of a pharmacogenetic test is the association between a particular HLA allele (HLA$B * 5701)$ and hypersensitivity reactions to abacavir [39]. 
Moreover, HLA-B*1502 screening is successful in patients who are prescribed carbamazepine, particularly in Asians. The HLAB*1502 allele is associated with carbamazepineinduced Stevens-Johnson syndrome (SJS) and toxic epidermal necrolysis (TEN) [27].

\section{Repurposed anti-COVID-19 drugs}

\section{Chloroquine (CQ)and hydroxychloroquine (HCQ)}

CQ and HCQ have been used to treat malaria for over 50 years. They were the first antiviral drugs officially indicated for COVID-19 in the U.S. as an FDA Emergency Use Authorization issued on March 28, 2020. This was later revoked on June 15, 2020 based on new data suggesting that the drug's potential benefits may not outweigh its known and potential risks [40]. However, a number of ongoing studies for both treatment and prevention of COVID-19 are still underway. HCQ and CQ inhibit major histocompatability complex (MHC) class II expression; production of IL-1, IFN $\alpha$ and TNF and interfere with cyclic GMP-AMP synthase activity partly by accumulating in lysosomes and autophagosomes of phagocytic cells and changing local $\mathrm{pH}$ concentrations [41]. CQ and HCQ were reported to be effective against SARS-CoV-2 with a $50 \%$ effective concentration (EC50) of $2.71 \mu \mathrm{M}$ and $4.51 \mu \mathrm{M}$ in Vero E6 cells, respectively [42].

SARS-CoV-2 uses ACE2 receptors expressed on host epithelial cells along with cofactor transmembrane protease, serine 2 (TMPRSS2) to enter the cell. HCQ and CQ inhibit virus entry by targeting the endosomal pathway. They increase the $\mathrm{pH}$ of endosomes and inhibit membrane fusion [43]. In addition, inhibition of SARS-CoV-2 could be partly due to differential glycosylation of both ACE2 and the spike protein [44]. Several variants in ACE2 including p.Met383Thr, p.Pro389His, and p.Asp427Tyr were identified in the African American and Latino American populations. These pathogenic variants in ACE2 may inhibit interaction with the $S$ protein and could influence the clinical efficacy of HCQ or CQ [45]. The ACE2 receptor N720D variant may enhance TMPRSS2 activation and subsequent viral entry [46]. HCQ and CQ may only work for TMPRSS2-absence patients who are infected by SARSCoV-2, and may have less effect or no effect for the patients with wild-type TMPRSS2 [47].

In patients with COVID-19, CQ has been administered orally at a dose of $300 \mathrm{mg}$ for adults, twice daily (bid) for a maximal duration of 10 days. HCQ therapy is started at a loading dose of $400 \mathrm{mg}$ bid. on day 1 and then lowered to $200 \mathrm{mg}$ bid (10 days average). A recent study showed that both drugs have favorable and unfavorable characteristics, but none showed clear evidence of benefit for early outpatient disease or prophylaxis [48].The most severe complications from use of HCQ and CQ include QTc prolongation and ventricular arrhythmias [49], which may pose a particular risk to critically ill patients. HCQ and CQ undergo $N$-dealkylation via CYP isozymes [50]. A few reports have described significance of gene polymorphisms in affecting HCQ or CQ treatment outcome. In African children with acute falciparum malaria, peak plasma $\mathrm{CQ}$ and DCQ concentrations were highly variable [51]. In malaria patients from Tanzania [52], India [53] and Sudan [54], the mean plasma CQ concentrations were higher in sensitive patients than in resistant patients. The carriers of CYP2C8-reduced activity alleles showed lower efficacy as compared with homozygous wild-type allele *1A [55]. $C Y P 2 C 8^{*} 4$ is a missense mutation, which promotes a lower enzyme activity in vitro than the wild-type allele $* 1 A$, and similarly $C Y P 2 C 8 * 2$ and $C Y P 2 C 8 * 3$ also present a markedly decreased activity in vitro [56]. Both CQ and HCQ are metabolized by hepatic cytochrome P450 CYP2D6, the expression of which varies among individuals as the result of genetic polymorphisms. High HCQ concentrations have been observed in individuals who are poor or intermediate CYP2D6 metabolizers (CYP2D6*4; CYP2D6*10) [57]. Both CQ and HCQ were reported to inhibit CYP2D6 activity [58]. They may potentiate other CYP2D6 substrates such as labetalol and carvedilol [59] and decrease the effectiveness of prodrugs reliant on CYP2D6 for activation such as codeine and tramadol [60]. There is no established clinical guidance related to CYP2D6 gene variants in CQ or HCQ use. Glucose-6-phosphate dehydrogenase (G6PD) deficiency is most common in the Mediterranean area, in Europe, in Middle East, Asia and parts of Africa. Genetic variants affecting G6PD activity show remarkably individual and ethnical differences [61]. More than 160 G6PD genetic variants have been identified including G6PD B (wild type), G6PD A (non-deficient type) and G6PD A (African deficient type). G6PD $376 \mathrm{G} / 202 \mathrm{~A}$ haplotype is the most common G6PD variants in sub-Saharan Africa [62]. CQ and HCQ use in individuals having genetic mutations in the G6PD may induce hemolysis and hemolytic anemia.

The blood group $\mathrm{ABO}$ gene encodes glycosyltransferases which determine addition of $\mathrm{N}$-acetylgalactosamine or galactose to $\mathrm{H}$ antigen and subsequently determines $\mathrm{A}$ and $\mathrm{B}$ antigens. Vasku et al. [63] identified an association of blood pressure with ACE I/D polymorphism and ABO blood group. Genetic variation within Fucosyltransferase 2 (FUT2) has been studied extensively in the context of human exposure. Homozygotes for the nonsense mutation (rs601338 G>A) that inactivates the FUT2 enzyme are unable to secrete $\mathrm{ABO}(\mathrm{H})$ histo-blood group antigens or express them on mucosal surfaces [64]. An association between the A allele and COVID-19 prevalence/mortality was recently confirmed [65]. ABO blood group, $\mathrm{Hb}$ genotype and G6PD status showed no significant 
influence on CQ treatment outcome in Nigerian children with uncomplicated malarial infection, but there was greater risk of developing resistance to $\mathrm{CQ}$ in $\mathrm{HbAA}$ than $\mathrm{HbAS}$ individuals [66]. Another well-recognized adverse effect of HCQ and CQ is retinopathy, which occurs more frequently with long term use and higher doses. Retinopathy occurred less frequently in those with the minor allele of ATP-binding cassette (ABC) transporters ABCA4 c.5814 A > G [67]. CQ and HCQ should be used with caution especially in combination with other drugs or at high doses potentially with monitoring of RBC or hemoglobin levels and genetic testing should be recommended.

\section{Azithromycin}

This macrolide antibiotic is used extensively in patients with viral infections to prevent severe respiratory tract infections Azithromycin-HCQ combination shows a synergistic effect on Covid-19 disease [68]. The pharmacokinetics (PKs) of azithromycin are influenced by the activity of P-glycoprotein (P-gp) transporter encoded by ABCB1. Genetic variation in ABCB1 showed up to a twofold lower peak azithromycin concentrations in 20 healthy volunteers after a single dose [69]. Higher systemic exposure to azithromycin is of particular concern when it is combined with HCQ or CQ because of their additive effects on QTc prolongation.

\section{Protease inhibitors}

\section{Lopinavir (LPV)/Ritonavir (RTV), LPV/r}

LPV blocks a postentry step in the MERS-CoV replication cycle, conferring this drug a promising potential agent for COVID-19 [70]. RTV blocks CYP3A-mediated metabolism of LPV thereby prolonging its exposure. LPV is metabolized primarily through CYP3A and transported by ABCB1 and ABCB2. RTV is metabolized by CYP2J2, CYP3A4, CYP3A5 and CYP2D6. RTV inhibits CYP3A and organic anion transporting polypeptides (OATP1B1 and OATP1B3), and may also induce other CYP isoforms [71]. RTV is enhancing the effect and concentrations of the medicines usually metabolized by CYP3A4, including LPV. RTV also increases the biotransformation of some drugs metabolized by glucuronidation catalyzed by UGT. The clinical relevance of these effects needs to be investigated. LPV/r was used in a regimen of $400 \mathrm{mg} / 100 \mathrm{mg}$ bid for adults for 10-21 days [72]. There is also an initiative to reformulate $\mathrm{LPV} / \mathrm{r}$ in a new extracellular vesicles delivery system [73].

Genetic screening of Apo lipoprotein E (APOE) and APOC3 can reduce the risk of hypertriglyceridemia and lipodystrophy associated with RTV [74]. Interindividual variations of LPV concentration were associated with
SLCO1B1. A pharmacogenomic analysis of LPV/RTV, including 1380 variants in 638 HIV-infected Caucasians, identified four significant variants. Clearance of LPV was higher in individuals with SLCO1B $1 * 4 / * 4$ and lower in individuals with two or more variant alleles of SLCO1B1*5, ABCC2 or a CYP3A [75]. The CYP3A4 polymorphism L292P (rs28371759, CYP*18B) is linked with increased CYP3A4 activity, thus facilitating the metabolism of drugs like LPV. L292P was reported to occur more in East Asians, indicating that East Asians may metabolize LPV and RTV more rapidly. There are about 66 coding SNPs in $A B C B 1$ gene [76]. The $3435 \mathrm{C}>\mathrm{T}$ is present in exon 26 of the ABCB 1 gene, involving a C-to-T transformation, and does not alter the amino acid isoleucine. The variant allele frequency of $3435 \mathrm{C}>\mathrm{T}$ in the Asian population differs significantly from the African and Caucasian population [77]. There are many non-synonymous polymorphisms in ABCB1 [78]. Among them, S893T, S893A (rs2032582), N21D (rs9282564) and S400N (rs2229109) can increase the drug concentration through decreasing the efflux of ABCB1. S893A carriers are found in all populations with high frequency, which is up to $90 \%$ in Africans. S893T carriers are almost East Asians, while N21D carriers are Europeans. These patients may have more response to the drugs transported by ABCB 1 .

\section{Atazanavir (ATV)}

ATV exhibits potent anti-HIV activity and good oral bioavailability. ATV inhibits SARS-CoV2 replication in both Vero cells and human epithelial pulmonary cells (A549). ATV is metabolized by CYP3A and is an inhibitor of CYP3A and UGT1A. The CPIC guideline for ATV considers several polymorphisms in UGT1A1, including a variable dinucleotide (TA) repeat within the gene promoter region (rs8175347, alleles $U G T 1 A 1 * 28$, $* 36$ and *37), and the SNPs rs4148323 (UGT1Al*6) and rs887829 $(U G T 1 A 1 * 80)$ [79]. The $U G T 1 A 1 * 28$ allele predisposes to severe hyperbilirubinemia in individuals exposed to ATV [80]. UGT1A1*28 homozygotes have the highest risk and UGT1A $1 * 28$ heterozygotes have an intermediate risk of developing hyperbilirubinemia [81]. The CPIC guidelines for pharmacogenomic prescribing of ATV recommend counseling on the likelihood of developing hyperbilirubinemia in UGT1A1*28/*28,*28/*37,*37/*37, and -364 TT genotype carriers before initiating therapy [79]. ATV metabolism is partially due to the P-gp efflux pump encoded by the multidrug resistance $1(M D R l)$ gene, which seems to increase plasma concentrations of ATV in the presence of 3435 variable genetic homozygosis $\mathrm{C} / \mathrm{C}$, exposing the patient to a risk of hyperbilirubinemia and severe jaundice. Polymorphism $238 \mathrm{G}>\mathrm{A}$ appears to be related to an early onset of lipodystrophy [82]. Several studies demonstrated 
that $A P O A 5$ gene polymorphisms $(1131 \mathrm{~T}>\mathrm{C}$ and $64 \mathrm{G}>$ C), APOC3 $(482 \mathrm{C}>\mathrm{T}, \quad 455 \mathrm{C}>\mathrm{T}, \quad 3238 \mathrm{C}>\mathrm{G})$, and ABCA1 $(2962 \mathrm{~A}>\mathrm{G})$ and APOE ( $\varepsilon 2$ and $\varepsilon 3$ haplotypes) are associated with a high risk of dyslipidemia [83].

\section{Non-nucleoside reverse transcriptase inhibitors (NNRTIs)}

\section{Favipiravir (FVP)}

FVP is a purine nucleic acid analog and potent RdRp) inhibitor. It has been shown to be effective in the treatment of influenza and Ebola virus disease [84]. FAV inhibits SARS-CoV-2 replication in Vero E6 cells [85]. FVP undergoes metabolism in the liver mainly by aldehyde oxidase and partially by xanthine oxidase. The efficacy of substrates of aldehyde oxidase such as azathioprine or allopurinol are associated with variants of aldehyde oxidase [86].

\section{Nevirapine (NVP)}

NVP is a NNRTI widely prescribed for HIV treatment. It is generally effective with some reported cases of hepatotoxicity and severe cutaneous adverse reactions. The HLA-DRB $1 * 01$, HLA-B*3505 and CYP2B6 gene polymorphisms have been associated with the onset of rash from NVP [87]. The CYP2B6 983 C allele was reported to confer a higher risk of SJS and TEN in a population of Mozambique treated with NVP. Polymorphism $\mathrm{C}>\mathrm{T}$ position 3435 of MDR1 was associated with reduced risk of hepatotoxicity [88]. Also, the ABCC10 (MDR7) polymorphism rs2125739 has been associated with plasma concentrations of NVP.

\section{Efavirenz (EFV)}

EFV is predominantly inactivated by CYP2B6, and patients with certain CYP2B6 genetic variants may be at increased risk for adverse effects [89]. In a genome-wide association study, CYP2B6 rs4803419 (g.15582 C > T) was independently associated with increased plasma EFV exposure [90]. Patients who were homozygous for the minor allele (g.15582 T/T) had plasma EFV concentrations comparable to CYP2B6 intermediate metabolizers (based on CYP2B6 c. $516 \mathrm{G}>\mathrm{T}$ and c. $983 \mathrm{~T}>\mathrm{C}$ status). CYP2B6 genotyping can possibly afford minimization of adverse effects with EFV, such as depression and suicidal tendencies, by tailoring the drug dose to the genotype of patients [91].

\section{Oseltamivir}

Oseltamivir targets the neuraminidase distributed on the surface of the influenza virus [92]. Several clinical trials are still evaluating the effectiveness of oseltamivir in treating SARS-CoV-2 infection [93]. Oseltamivir needs to be activated by carboxylesterase 1 (CES1) into its active metabolite, oseltamivir carboxylate [94]. G143E variants were reported to be $3.7 \%, 4.3 \%, 2.0 \%$ and $0 \%$ in White, Black, Hispanic and Asian populations, respectively [95]. A clinical study showed that G143E heterozygotes exhibited $18 \%$ greater AUC of oseltamivir and 23\% smaller AUC ratios of oseltamivir carboxylate to oseltamivir compared to individuals with the 143GG genotype [96]. Significant inter-individual variability in oseltamivir PK and in antiviral effects have been consistently reported in clinical studies [97]. CES1 and ABCB1 genetic variants have the potential to serve as valid biomarkers for the prediction of oseltamivir activation and the optimization of oseltamivir pharmacotherapy [98].

\section{Remdesivir}

Preliminary clinical trials demonstrated remdesivir effectiveness for the treatment of COVID-19 [70]. Remdesivir is primarily metabolized by hydrolase in vivo [99]. It has a generally low risk of significant genetic PKs interactions. In vitro studies suggest that it is a substrate for drug metabolizing enzymes CYP2C8, CYP2D6, and CYP3A4, as well as a substrate for OATP1B1 and P-gp transporters [100]. Thus, known variants of these genes could theoretically affect the PKs of remdesivir. According to current knowledge, no guideline recommends pharmacogenetic testing before remdesivir administration.

\section{Biological Drugs}

\section{Anakinra}

Anakinra is a biologic medicine used in the treatment of rheumatoid arthritis (RA) in combination with methotrexate. Anakinra inhibits the IL- $1 \alpha$ and IL- $1 \beta$ and has been used with some success in several small studies in patients with COVID-19 [101]. A relationship between the infrequent IL-1a $+4845 \mathrm{G} / \mathrm{T}$ polymorphism and a significant better response to anakinra treatment was reported [102].

\section{Tocilizumab (TCZ)}

Treatment with TCZ may reduce the risk of invasive mechanical ventilation or death in patients with severe COVID-19 pneumonia [103]. In vitro studies in hepatocytes have shown that TCZ blocks the downregulation of CYP450 (mainly CYP3A4) that is caused by IL6 [104]. Several genetic biomarkers have been associated with the efficacy of TCZ in RA, including FCGR3A, IL6R, CD69, and GALNT18 [105]. The only genetic variants potentially 
involving TCZ's PKs are in the FCGR3A gene. In 87 patients with RA treated with TCZ, FCGR3A rs396991TT genotype showed higher response at 12 months. Polymorphisms of IL6R are considered to affect the intracellular signaling pathway of IL-6 receptor bound to TCZ [106]. In contrast, variants in CD69 and GALNT18 are thought to have limited direct effects on TCZ. Genetic variation in IL6R may aid in predicting TCZ therapy outcome in COVID-19 patients. To date, no pharmacogenetic testing is recommended for TCZ.

\section{Eculizumab}

Multiple therapeutic agents targeting complement activation are currently being studied for COVID-19 [107] Eculizumab is a monoclonal antibody that specifically binds to C5 with high affinity, thereby inhibiting its cleavage to $\mathrm{C} 5 \mathrm{a}$ and $\mathrm{C} 5 \mathrm{~b}$ and preventing the generation of the terminal complement complex C5b-9. AMY-101, a C3 inhibitor, is currently being tested in patients with COVID-19 [108]. The combination of clinical indicators of lung injury progression with known biomarkers of inflammation (C- reactive protein, plasma IL-6 levels and ferritin) would allow identification of patients that could benefit from complement inhibition [109].

\section{Heme Oxygenase 1 (HO-1) up-regulators}

Human $\mathrm{HO}$ protein has an important anti-inflammatory role in attenuating serious conditions like thrombosis, sepsis, tissue damage and fibrinogenesis, all of which are associated with SARS-CoV-2 infections [110]. The inducibility of HO-1 is regulated by the promoter region guanosine thymidine dinucleotide (GT)n repeats mutation [111]. Patients with COVID-19 complications have longer GT sequences [112]. Inducing HO-1 expression may prevent SARS-CoV-2-induced pulmonary complications [113].

Hemin, a substrate for HO-1 obtained from the breakdown of RBCs, is FDA approved for treatment of porphyria and is effective in blocking Zika viral replication [114]. The hemin-induced HO-1 cytoprotective pathway appears as a consistent target to control COVID-19. Heme arginate increases HO-1 levels by inhibiting delta-aminolevulinate synthase and so it can improve inflammation and viral infections [115]. Heme arginate is able to induce CYP2D6 and CYP3A4 [116]. CQ, HCQ, azithromycin, and remdesivir decrease heme production, in part, by inhibiting CYP induction, thus decreasing the demand for heme. These drugs also display interactions with the CYP system, which make maintaining safe effective therapeutic drug levels a challenge. Up-regulation of HO-1 is especially important in COVID-19 patients with the longer GT allele HO-1 polymorphism, and those with CYP2D6 polymorphisms that lead to supra- or sub-therapeutic drug levels. A synergistic anti-inflammatory effect may be obtained by the combination of heme arginate with repurposed anti-COVID-19 drugs that are not metabolized by CYP2D6/3A4. Recently, the glucocorticoid dexamethasone was found to save many severely ill COVID-19 patients [117]. Dexamethasone reduces hemolysis and induces HO-1 in macrophages [118], leading to attenuation of the severity of disease in COVID-19 patients. There are a number of naturally occurring substances that are capable of upregulating HO-1 [119] such as thymoquinone, neem leaf extract, resveratrol and curcumin.

\section{Inhibitors of the renin-angiotensin-aldosterone system (RAAS)}

There are some pharmacogenetic predictors of disposition and response of RAAS inhibitors [120]. Losartan, an ACE receptor blocker and is metabolized by CYP2C9 [121]. Genotyping some of Cyp 2C9 polymorphisms may affect losartan clinical benefits. The most common reduced-function variants are $C Y P 2 C 9 * 2$ (Arg144Cys), and $C Y P 2 C 9 * 3$ (Ile359Leu). CYP2C9 genotyping could be beneficial for dose adjustment. Other pharmacogenetic biomarkers, namely $A B C B 1$ gene variants, could be useful predictors of losartan response [122]. The most relevant polymorphisms in $A B C B 1$ are C3435T (rs1045642), G2677T/A (rs2032582) and C1236T (rs1128503) [123]. Regarding ACE inhibitors, $A C E$ rs1799752 was related to variability in ACE inhibitors [124, 125]. This polymorphism consists of a 50-nucleotide deletion (del). Patients with the del/del diplotype correlated with a worse clinical outcome. The best pharmacogenetic predictor for spironolactone effectiveness is rs4961, located in the alpha-adducin gene, which predicts drug response in combination with furosemide [126]. Carriers of the $\mathrm{G}$ allele exhibited a better response to therapy compared with $\mathrm{T}$ allele carriers.

\section{Anthelmintics}

\section{Ivermectin}

Ivermectin has the potential to prevent viral replication of a broad spectrum of viruses. It has shown inhibition against SARS-CoV-2 in vitro through inhibition of Importin $\alpha / \beta 1$ (IMP $\alpha / \beta 1)$-mediated nuclear import of viral proteins [127]. Ivermectin is metabolized by CYP3A4. Ivermectin is both a substrate and a potent inducer of the P-gp. P-gp inhibitors can increase ivermectin plasma levels [128].

\section{Nitazoxanide}

Nitazoxanide and its active metabolite, tizoxanide have demonstrated potent activity against SARS CoV-2 and MERS 
$\mathrm{CoV}$ in Vero E6 cells. Nitazoxanide upregulates the innate antiviral mechanisms by broadly amplifying cytoplasmic RNA sensing and type I IFN pathways [85]. Metabolism of nitazoxanide occurs via hydrolysis and then conjugation via glucuronidation. Nitazoxanide has a very favorable drug interaction profile with no known clinically significant drug interaction concerns. So far, no pharmacogenetic studies regarding efficacy or toxicity of nitazoxanide were rported.

\section{Conclusions}

Currently, no direct evidence of PGx data in patients with COVID-19 is available. There are clear mechanisms by which genetic determinants may alter the therapeutic outcome of the current repurposed drugs for COVID-19. There is a need to do more PGx studies for COVID-19 repurposed therapies to establish evidence-based guidelines for genetic testing. The article identifies some potential associations between genetic variants and clinical outcomes of COVID19 therapy. Incorporating the knowledge of PGx in the prospective clinical investigations of repurposed drugs during COVID-19 therapy is necessary to achieve safe and effective dosing and to reduce severity of adverse effects.

\section{Compliance with ethical standards}

Conflict of interest The author declares that he has no conflict of interest.

Publisher's note Springer Nature remains neutral with regard to jurisdictional claims in published maps and institutional affiliations.

\section{References}

1. Zhang L, Liu Y. Potential interventions for novel coronavirus in China: a systematic review. J Med Virol. 2020;92:479-90.

2. Masters PS. Coronavirus genomic RNA packaging. Virology. 2019;537:198-207.

3. Benton DJ, Wrobel AG, Xu P, Roustan C, Martin SR, Rosenthal $\mathrm{PB}$, et al. Receptor binding and priming of the spike protein of SARS-CoV-2 for membrane fusion. Nature. 2020. https://doi. org/10.1038/s41586-020-2772-0.

4. Prajapat M, Sarma P, Shekhar N, Avti P, Sinha S, Kaur H, et al. Drug targets for corona virus: a systematic review. Indian $\mathrm{J}$ Pharmacol. 2020;52:56-65.

5. Baden LR, Rubin EJ. Covid-19 - the search for effective therapy. N. Engl J Med. 2020;382:1851-2.

6. Wu R, Wang L, Kuo HD, Shannar A, Peter R, Chou PJ, et al. An update on current therapeutic drugs treating COVID-19. Curr Pharm Rep. 2020;11:1-15.

7. Jean SS, Hsueh PR. Old and re-purposed drugs for the treatment of COVID-19. Expert Rev Anti Infect Ther 2020;18:843-7.

8. Magro G. COVID-19: review on latest available drugs and therapies against SARS-CoV-2. Coagulation and inflammation cross-talking. Virus Res. 2020;286:198070.
9. Venkatasubbaiah M, Dwarakanadha Reddy P, Satyanarayana SV. Literature-based review of the drugs used for the treatment of COVID-19. Curr Med Res Pract. 2020;10:100-9.

10. Drożdżal S, Rosik J, Lechowicz K, Machaj F, Kotfis K, Ghavami S, et al. FDA approved drugs with pharmacotherapeutic potential for SARS-CoV-2 (COVID-19) therapy. Drug Resist Updat. 2020;53:100719. https://doi.org/10.1016/j.drup. 2020.100719.

11. Santos J, Brierley S, Gandhi MJ, Cohen MA, Moschella PC, Declan ABL. Repurposing therapeutics for potential treatment of SARS-CoV-2: a review. Viruses 2020;12:705.

12. Bibi N, Gul S, Ali J, Kamal MA. Viroinformatics approach to explore the inhibitory mechanism of existing drugs repurposed to fight against COVID-19. Eur J Pharmacol. 2020;885:173496. https://doi.org/10.1016/j.ejphar.2020.173496.

13. Singh TU, Parida S, Lingaraju MC, Kesavan M, Kumar D, Singh RK. Drug repurposing approach to fight COVID-19. Pharm Rep. 2020;5:1-30.

14. Lovato ECW, Barboza LN, Wietzikoski S, de Souza ANV, Auth PA, Junior AG, et al. Repurposing drugs for the management of patients with confirmed coronavirus disease 2019 (COVID-19). Curr Pharm Des. 2020. https://doi.org/10. 2174/1381612826666200707121636.

15. Khadka S, Yuchi A, Shrestha DB, Budhathoki P, Al-Subari SMM, Ziad Alhouzani TM, et al. Repurposing drugs for COVID-19: an approach for treatment in the pandemic. Altern Ther Health Med. 2020:26:100-7.

16. Hossen MS, Barek MA, Jahan N, Safiqul Islam M. A review on current repurposing drugs for the treatment of COVID-19: reality and challenges. SN Compr Clin Med. 2020:1-13. [Epub ahead of print].

17. Gyanwali P, Sharma S, Pant S, Koirala P, Adhikari K, Koirala J, et al. Safety and efficacy of different therapeutic interventions on prevention and treatment of COVID-19. J Nepal Health Res Counc 2020;18:151-8.

18. Takahashi T, Luzum JA, Nicol MR, Jacobson PA. Pharmacogenomics of COVID-19 therapies. NPJ Genom Med 2020;5 (Aug):35. https://doi.org/10.1038/s41525-020-00143-y.

19. Zubiaur P, Koller D, Saiz-Rodríguez M, Navares-Gómez M, Abad-Santos F. Important pharmacogenetic information for drugs prescribed during the SARS-CoV-2 infection (COVID-19). Clin Transl Sci. 2020. https://doi.org/10.1111/cts.12866.

20. Huddart R, Whirl-Carrillo M, Altman RB, Klein TE. PharmGKB tutorial for pharmacogenomics of drugs potentially used in the context of COVID-19. Clin Pharmacol Ther. 2020. https://doi. org/10.1002/cpt.2067.

21. Tomalik-Scharte D, Lazar A, Fuhr U, Kirchheiner J. The clinical role of genetic polymorphisms in drug-metabolizing enzymes. Pharmacogenomics J 2008;8(Feb):4-15.

22. Ventola CL. Role of pharmacogenomic biomarkers in predicting and improving drug response: part 1: the clinical significance of pharmacogenetic variants. P T. 2013;38:545-60.

23. Silvado CE, Terra VC, Twardowschy CA. CYP2C9 polymorphisms in epilepsy: influence on phenytoin treatment. Pharmgenomics Pers Med 2018;11:51-58.

24. Wigle TJ, Jansen LE, Teft WA, Kim RB. Pharmacogenomics guided-personalization of warfarin and tamoxifen. J Pers Med 2017;7:20. https://doi.org/10.3390/jpm7040020.

25. Zhang YJ, Li MP, Tang J, Chen XP. Pharmacokinetic and pharmacodynamic responses to clopidogrel: evidences and perspectives. Int J Environ Res Public Health 2017;14:301. https:// doi.org/10.3390/ijerph14030301.

26. Yu M, Liu M, Zhang W, Ming Y. Pharmacokinetics, pharmacodynamics and pharmacogenetics of tacrolimus in kidney transplantation. Curr Drug Metab 2018;19:513-22. 
27. Relling MV, Klein TE, Gammal RS, Whirl-Carrillo M, Hoffman JM, Caudle KE. The clinical pharmacogenetics implementation consortium: 10 years later. Clin Pharm Ther 2020;107:171-5.

28. Fujita K, Sparreboom A. Pharmacogenetics of irinotecan disposition and toxicity: a review. Curr Clin Pharmacol. 2010;5:209-17.

29. Scott S. Personalizing medicine with clinical pharmacogenetics. Genet Med. 2011;13:987-95.

30. Patil J. Pharmacogenetics and pharmacogenomics: a brief introduction. J Pharmacovigil. 2015;2:3-4.

31. Vogel F. Moderne Probleme der Humangenetik. Ergebn Inn Med Kinderheilkd. 1959;12:52-125.

32. Ma JD, Lee KC, Kuo GM. Clinical application of pharmacogenomics. J Pharm Pr. 2012;25:417-27.

33. Whirl-Carrillo M, McDonagh EM, Hebert JM, Gong L, Sangkuhl K, Thorn CF, et al. Pharmacogenomics knowledge for personalized medicine. Clin Pharm Ther. 2012;92:414-7.

34. Gamazon ER, Huang RS, Cox NJ. SCAN: a systems biology approach to pharmacogenomic discovery. Methods Mol Biol. 2013;1015:213-24.

35. Gamazon ER, Duan S, Zhang W, Huang RS, Kistner EO, Dolan ME. PACdb: a database for cell-based pharmacogenomics. Pharmacogenet Genomics. 2010;20:269-73.

36. Hockings JK, Pasternak AL, Erwin AL, Mason NT, Eng C, Hicks JK. Pharmacogenomics: an evolving clinical tool for precision medicine. Cleve Clin J Med 2020;87:91-99.

37. Yang Y, Peter I, Scott SA. Pharmacogenetics in Jewish populations. Drug Metab Drug Interact. 2014;29:221-33.

38. Drew L. Pharmacogenetics: the right drug for you. Nature. 2016;537:S60-62.

39. Mallal S, Phillips E, Carosi G, Molina JM, Workman C, Tomazic $\mathrm{J}$, et al. PREDICT-1 study team. HLA-B*5701 screening for hypersensitivity to abacavir. N Engl J Med. 2008;358:568-79.

40. FDA Letter to BARDA. https://www.fda.gov/media/138945/ download (2020).

41. Schrezenmeier E, Dörner T. Mechanisms of action of hydroxychloroquine and chloroquine: implications for rheumatology. Nat Rev Rheumatol 2020;16:155-66.

42. Yao X, Ye F, Zhang M, Cui C, Huang B, Niu P, et al. In vitro antiviral activity and projection of optimized dosing design of hydroxychloroquine for the treatment of severe acute respiratory syndrome coronavirus 2 (SARS-CoV-2). Clin Infect Dis. 2020;71:732-9.

43. Sanders JM, Monogue ML, Jodlowski TZ, Cutrell JB. Pharmacologic treatments for coronavirus disease 2019 (COVID-19): a review. JAMA. 2020;323:1824-36.

44. Savarino A, Di Trani L, Donatelli I, Cauda R, Cassone A. New insights into the antiviral effects of chloroquine. Lancet Infect Dis. 2006;6:67-69.

45. Rosenberg ES, Dufort EM, Udo T, Wilberschied LA, Kumar J, Tesoriero $\mathrm{J}$, et al. Association of treatment with hydroxychloroquine or azithromycin with in-hospital mortality in patients With COVID-19 in New York State. JAMA. 2020;323:2493-502.

46. Al-Mulla F, Mohammad A, Al Madhoun A, Haddad D, Ali H, Eaaswarkhanth $\mathrm{M}$, et al A comprehensive germline variant and expression analyses of ACE2, TMPRSS2 and SARS-CoV-2 activator FURIN genes from the Middle East: Combating SARSCoV-2 with precision medicine. bioRxiv preprint https://doi.org/ 10.1101/2020.05.16.099176.

47. Ou T, Mou H, Zhang L, Ojha A, Choe H, Farzan M. Hydroxychloroquine-mediated inhibition of SARS-CoV-2 entry is attenuated by TMPRSS2. bioRxiv preprint https://doi.org/10. $1101 / 2020.07 .22 .216150$.

48. Meo SA, Zaidi SZA, Shang T, Zhang JY, Al-Khlaiwi T, Bukhari IA, et al. Biological, molecular and pharmacological characteristics of chloroquine, hydroxychloroquine, convalescent plasma, and remdesivir for COVID-19 pandemic: a comparative analysis. J King Saud Univ Sci 2020;32:3159-66.

49. Tönnesmann E, Kandolf R, Lewalter T. Chloroquine cardiomyopathy - a review of the literature. Immunopharmacol Immunotoxicol. 2013;35:434-42.

50. Lim HS, Im JS, Cho JY, Bae KS, Klein TA, Yeom JS, et al. Pharmacokinetics of hydroxychloroquine and its clinical implications in chemoprophylaxis against malaria caused by Plasmodium vivax. Antimicrob Agents Chemother. 2009;53:1468-75.

51. Hellgren U, Alván G, Jerling M. On the question of interindividual variations in chloroquine concentrations. Eur J Clin Pharmacol. 1993;45:383-5.

52. Walker O, Dawodu AH, Adeyokunnu AA, Salako LA, Alvan G. Plasma chloroquine and desethylchloroquine concentrations in children during and after chloroquine treatment for malaria. Br J Clin Pharmacol 1983;16:701-5.

53. Dua VK, Gupta NC, Kar PK, Nand J, Edwards G, Sharma VP, et al. Chloroquine and desethylchloroquine concentrations in blood cells and plasma from Indian patients infected with sensitive or resistant Plasmodium falciparum. Ann Trop Med Parasitol. 2000;94:565-70.

54. Karim EA, Ibrahim KE, Hassabalrasoul MA, Saeed BO, Bayoumi RA. A study of chloroquine and desethylchloroquine plasma levels in patients infected with sensitive and resistant malaria parasites. J Pharm Biomed Anal. 1992;10:219-23.

55. Sortica V, Lindenau J, Cunha M, Ohnishi M, Ventura A, Ribeiro-dos-Santos A, et al. The effect of SNPs in CYP450 in chloroquine/primaquine Plasmodium vivax malaria treatment. Pharmacogenomics. 2016;17:1903-11.

56. Dai D, Zeldin DC, Blaisdell JA, Chanas B, Coulter SJ, Ghanayem BI, et al. Polymorphisms in human CYP2C8 decrease metabolism of the anticancer drug paclitaxel and arachidonic acid. Pharmacogenetics. 2001;11:597-607.

57. Lee J, Vinayagamoorthy N, Han K, Kwok S, Ju J, Park K, et al. Association of polymorphisms of cytochrome P450 2D6 with blood hydroxychloroquine levels in patients with systemic lupus erythematosus. Arthritis Rheumatol. 2016;68:184-190.

58. Masimirembwa CM, Hasler JA, Johansson I. Inhibitory effects of antiparasitic drugs on cytochrome P450 2D6. Eur J Clin Pharmacol. 1995;48:35-38.

59. Somer M, Kallio J, Pesonen U, Pyykkö K, Huupponen R, Scheinin M. Influence of hydroxychloroquine on the bioavailability of oral metoprolol. Br J Clin Pharmacol. 2000;49:549-54.

60. Kirchheiner J, Keulen JT, Bauer S, Roots I, Brockmöller J. Effects of the CYP2D6 gene duplication on the pharmacokinetics and pharmacodynamics of tramadol. J Clin Psychopharmacol. 2008;28:78-83.

61. Nouraie M, Reading NS, Campbell A, Minniti CP, Rana SR, Luchtman-Jones L, et al. Association of G6PD with lower haemoglobin concentration but not increased haemolysis in patients with sickle cell anaemia. Br J Haematol. 2010;150:218-25.

62. Clarke GM, Rockett K, Kivinen K, Hubbart C, Jefreys AE, Rowlands K, et al. Characterisation of the opposing efects of G6PD defciency on cerebral malaria and severe malarial anaemia. Elife. 2017;6:15085.

63. Vasku A, Soucek M, Hajek D, Holla V, Znojil V, Vacha I. Association analysis of 24-h blood pressure records with I/D ACE gene polymorphism and ABO blood group system. Physiol Res. 1999;48:99-104.

64. Hazra A, Kraft P, Selhub J, Giovannucci EL, Thomas G, Hoover $\mathrm{RN}$, et al. Common variants of FUT2 are associated with plasma vitamin B12 levels. Nat Genet. 2008;40:1160-2.

65. Delanghe JR, De Buyzere ML, Speeckaert MM. C3 and ACE1 polymorphisms are more important confounders in the spread and outcome of COVID-19 in comparison with ABO polymorphism. Eur J Prev Cardiol. 2020;27:1331-2. 
66. Nneji C, Adedapo A, Okorie P, Ademowo P. Chloroquine resistance and host genetic factors among nigerian children with uncomplicated P. falciparum Infection. Arch Med. 2015;7:1-9.

67. Grassmann F, Bergholz R, Mändl J, Jägle H, Ruether K, Weber $\mathrm{BH}$. Common synonymous variants in $\mathrm{ABCA} 4$ are protective for chloroquine induced maculopathy (toxic maculopathy). BMC Ophthalmol. 2015;15:18. https://doi.org/10.1186/s12886-0150008-0.

68. Gautret P, Lagier JC, Parola P, Hoang VT, Meddeb L, Mailhe M, et al. Hydroxychloroquine and azithromycin as a treatment of COVID-19: results of an open-label non-randomized clinical trial. Int J Antimicrob Agents. 2020;56:105949. https://doi.org/ 10.1016/j.ijantimicag.2020.105949.

69. He XJ, Zhao LM, Qiu F, Sun YX, Li-Ling J. Influence of ABCB1 gene polymorphisms on the pharmacokinetics of azithromycin among healthy Chinese Han ethnic subjects. Pharm Rep. 2009;61:843-50.

70. Costanzo M, De Giglio MAR, Roviello GN. SARS-CoV-2: recent reports on antiviral therapies based on lopinavir/ritonavir, darunavir/umifenovir, hydroxychloroquine, remdesivir, favipiravir and other drugs for the treatment of the new coronavirus. Curr Med Chem. 2020;27:4536-41.

71. Larson KB, Wang K, Delille C, Otofokun I, Acosta EP. Pharmacokinetic enhancers in HIV therapeutics. Clin Pharmacokinet. 2014;53:865-72.

72. Young BE, Ong SWX, Kalimuddin S, Low JG, Tan SY, Loh J, et al. Epidemiologic features and clinical course of patients infected with SARS-CoV-2 in Singapore. AMA. 2020;323:1488-94.

73. Kumar S, Zhi K, Mukherji A, Gerth K. Repurposing antiviral protease inhibitors using extracellular vesicles for potential therapy of COVID-19. Viruses. 2020;12:486. https://doi.org/10. 3390/v12050486.

74. Murphy RL, Berzins B, Zala C, Fichtenbaum C, Dube MP, Guaraldi G, et al. SABAR Study Team. Change to atazanavir/ ritonavir treatment improves lipids but not endothelial function in patients on stable antiretroviral therapy. AIDS. 2010;24:885-90.

75. Lubomirov R, di Iulio J, Fayet A, Colombo S, Martinez R, Marzolini C, et al. Swiss HIV Cohort Study. ADME pharmacogenetics: investigation of the pharmacokinetics of the antiretroviral agent lopinavir coformulated with ritonavir. Pharmacogenet Genomics. 2010;20:217-30.

76. Wolf SJ, Bachtiar M, Wang J, Sim TS, Chong SS, Lee CG. An update on $\mathrm{ABCB} 1$ pharmacogenetics: insights from a 3D model into the location and evolutionary conservation of residues corresponding to SNPs associated with drug pharmacokinetics. Pharmacogenomics J. 2011;11:315-25.

77. Balram C, Sharma A, Sivathasan C, Lee EJ. Frequency of C3435T single nucleotide MDR1 genetic polymorphism in an Asian population: phenotypic-genotypic correlates. Br J Clin Pharmacol 2003;56:78-83.

78. Tulsyan S, Mittal R, Mittal B. The effect of ABCB1 polymorphisms on the outcome of breast cancer treatment. Pharmacogenomics Personalized Med. 2016;9:47-58.

79. Gammal RS, Court MH, Haidar CE, Iwuchukwu OF, Gaur AH, Alvarellos $\mathrm{M}$, et al. Clinical pharmacogenetics implementation consortium (CPIC) guideline for UGT1A1 and atazanavir prescribing. Clin Pharm Ther. 2016;99:363-9.

80. Turatti L, Sprinz E, Lazzaretti RK, Kuhmmer R, Agnes G, Silveira $\mathrm{JM}$, et al. $U G T 1 A 1 * 28$ variant allele is a predictor of severe hyperbilirubinemia in HIV-infected patients on HAART in Southern Brazil. AIDS Res Hum Retroviruses. 2012;28:1015-18.

81. Busti AJ, Hall RG, Margolis DM. Atazanavir for the treatment of human immunodeficiency virus infection. Pharmacotherapy. 2004;24:1732-47.

82. Asensi V, Rego C, Montes AH, Collazos J, Carton JA, Castro $\mathrm{MG}$, et al. IL-1beta $(+3954 \mathrm{C} / \mathrm{T})$ polymorphism could protect human immunodeficiency virus (HIV)-infected patients on highly active antiretroviral treatment (HAART) against lipodystrophic syndrome. Genet Med. 2008;10:215-23.

83. Zanone Poma B, Riva A, Nasi M, Cicconi P, Broggini V, Lepri $\mathrm{AC}$, et al. Genetic polymorphisms differently influencing the emergence of atrophy and fat accumulation in HIV-related lipodystrophy. AIDS. 2008;22:1769-78.

84. Du YX, Chen XP. Favipiravir: pharmacokinetics and concerns about clinical trials for 2019-nCoV infection. Clin Pharmacol Ther. 2020. https://doi.org/10.1002/cpt.1844.

85. Choy KT, Wong AY, Kaewpreedee P, Sia SF, Chen D, Hui KPY, et al. Remdesivir, lopinavir, emetine, and homoharringtonine inhibit SARS-CoV-2 replication in vitro. Antivir Res. 2020;178:104786. https://doi.org/10.1016/j.antiviral. 2020.104786.

86. Madelain V, Nguyen TH, Olivo A, de Lamballerie X, Guedj J, Taburet AM, et al. Ebola virus infection: review of the pharmacokinetic and pharmacodynamic properties of drugs considered for testing in human efficacy trials. Clin Pharmacokinet. 2016;55:907-23.

87. Martin AM, Nolan D, James I, Cameron P, Keller J, Moore C, et al. Predisposition to nevirapine hypersensitivity associated with HLA-DRB1*0101 and abrogated by low CD4 T-cell counts. AIDS. 2005;19:97-99.

88. Vitezica ZG, Milpied B, Lonjou C, Borot N, Ledger TN, Lefebvre A, et al. HLA-DRB $1 * 01$ associated with cutaneous hypersensitivity induced by nevirapine and efavirenz. AIDS. 2008;22:540-1.

89. McDonagh EM, Lau JL, Alvarellos ML, Altman RB, Klein TE. PharmGKB summary: Efavirenz pathway, pharmacokinetics. Pharmacogenet Genomics. 2015;25:363-76.

90. Holzinger ER, Grady B, Ritchie MD, Ribaudo HJ, Acosta EP, Morse GD, et al. Genome-wide association study of plasma efavirenz pharmacokinetics in AIDS Clinical Trials Group protocols implicates several CYP2B6 variants. Pharmacogenet Genomics. 2012;22:858-67.

91. Desta Z, Gammal RS, Gong L, Whirl-Carrillo M, Gaur AH, Sukasem C, et al. Clinical pharmacogenetics implementation consortium (CPIC) guideline for CYP2B6 and efavirenz-containing antiretroviral therapy. Clin Pharm Ther. 2019;106:726-33.

92. McClellan K, Perry CM. Oseltamivir. Drugs. 2001;61:263-83.

93. Rosa SGV, Santos WC. Clinical trials on drug repositioning for COVID-19 treatment. Rev Panam Salud Publica. 2020;44:e40 https://doi.org/10.26633/RPSP.2020.40. eCollection 2020.

94. Shi J, Wang X, Eyler RF, Liang Y, Liu L, Mueller BA, et al. Association of oseltamivir activation with gender and carboxylesterase 1 genetic polymorphisms. Basic Clin Pharm Toxicol. 2016;119:555-61.

95. Zhu HJ, Markowitz JS. Activation of the antiviral prodrug oseltamivir is impaired by two newly identified carboxylesterase 1 variants. Drug Metab Dispos. 2009;37:264-7.

96. Tarkiainen EK, Backman JT, Neuvonen M, Neuvonen PJ, Schwab M, Niemi M. Carboxylesterase 1 polymorphism impairs oseltamivir bioactivation in humans. Clin Pharm Ther. 2012;92:68-71.

97. Dobson J, Whitley RJ, Pocock S, Monto AS. Oseltamivir treatment for influenza in adults: a meta-analysis of randomised controlled trials. Lancet. 2015;385:1729-37.

98. Liu S, Wang C, Chen Y, Peng S, Chen X, Tan Z. Association of SLC15A1 polymorphisms with susceptibility to dyslipidaemia in a Chinese Han population. J Clin Pharm Ther. 2019;44:868-74.

99. Warren TK, Jordan R, Lo MK, Ray AS, Mackman RL, Soloveva $\mathrm{V}$, et al. Therapeutic efficacy of the small molecule GS-5734 against Ebola virus in rhesus monkeys. Nature. 2016;531:381-5.

100. Fact Sheet For Health Care Providers: Emergency Use Authorization (EUA) of Remdesivir (GS-5734TM). https://www.fda.gov/ media/137566/download (2020). 
101. Cavalli G, De Luca G, Campochiaro C, Della-Torre E, Ripa M, Canetti D, et al. Interleukin-1 blockade with high-dose anakinra in patients with COVID-19, acute respiratory distress syndrome, and hyperinflammation: a retrospective cohort study. Lancet Rheumatol. 2020;2:e325-e331.

102. Camp NJ, Cox A, Di Giovine FS, McCabe D, Rich W, Duff GW. Evidence of a pharmacogenomic response to interleukin-l receptor antagonist in rheumatoid arthritis. Genes Immun. 2005;6:467-71.

103. Kewan T, Covut F, Al-Jaghbeer MJ, Rose L, Gopalakrishna KV, Akbik B. Tocilizumab for treatment of patients with severe COVID-19: A retrospective cohort study. EClinicalMed. 2020; 24:100418.

104. Long TJ, Cosgrove PA, Dunn RT, Stolz DB, Hamadeh H, Afshari $\mathrm{C}$, et al. Modeling therapeutic antibody-small molecule drug-drug interactions using a threedimensional perfusable human liver coculture platform. Drug Metab Dispos. 2016;44:1940-8.

105. iménez Morales A, Maldonado-Montoro M, Martínez de la Plata JE, Pérez Ramírez C, Daddaoua A, Alarcón Payer C, et al. FCGR2A/FCGR3A gene polymorphisms and clinical variables as predictors of response to tocilizumab and rituximab in patients with rheumatoid arthritis. J Clin Pharmacol. 2019;59:517-31.

106. Maldonado-Montoro $\mathrm{M}$, Cañadas-Garre $\mathrm{M}$, GonzálezUtrilla A, Ángel, Calleja-Hernández M. Influence of IL6R gene polymorphisms in the effectiveness to treatment with tocilizumab in rheumatoid arthritis. Pharmacogenomics J. 2018;18:167-72.

107. Java A, Apicelli AJ, Liszewski MK, Coler-Reilly A, Atkinson JP, Kim AH, et al. The complement system in COVID-19: friend and foe? JCI Insight. 2020;5:e140711. https://doi.org/10.1172/ jci.insight. 140711.

108. Risitano AM, Mastellos DC, Huber-Lang M, Yancopoulou D, Garlanda C, Ciceri F, et al. Complement as a target in COVID19? Nat Rev Immunol. 2020;20:343-4.

109. Laurence J, Mulvey JJ, Seshadri M, Racanelli A, Harp J, Schenck EJ, et al. Anti-complement C5 therapy with eculizumab in three cases of critical COVID-19. Clin Immunol. 2020;219:108555. https://doi.org/10.1016/j.clim.2020.108555.

110. Batra N, De Souza C, Batra J, Raetz AG, Yu AM. The HMOX1 Pathway as a Promising Target for the Treatment and Prevention of SARS-CoV-2 of 2019 (COVID-19). Int J Mol Sci. 2020;21:6412. https://doi.org/10.3390/ijms21176412.

111. Bao W, Song F, Li X, Rong S, Yang W, Wang D, et al. Association between heme oxygenase-1 gene promoter polymorphisms and type 2 diabetes mellitus: a HuGE review and metaanalysis. Am J Epidemiol. 2010;172:631-6.

112. Fakhouri EW, Peterson SJ, Kothari J, Alex R, Shapiro JI, Abraham NG. Genetic polymorphisms complicate COVID-19 therapy: pivotal role of HO-1 in cytokine storm. Antioxid (Basel) 2020;9(Jul):636. https://doi.org/10.3390/antiox9070636.

113. Wagener FADTG, Pickkers P, Peterson SJ, Immenschuh S, Abraham NG. Targeting the heme-heme oxygenase system to prevent severe complications following COVID-19 infections. Antioxid (Basel). 2020;9:540. https://doi.org/10.3390/a ntiox 9060540 .
114. Huang H, Falgout B, Takeda K, Yamada KM, Dhawan S. Nrf2dependent induction of innate host defense via heme oxygenase1 inhibits Zika virus replication. Virology. 2017;503:1-5.

115. Hill-Batorski L, Halfmann P, Neumann G, Kawaoka Y. The cytoprotective enzyme heme oxygenase-1 suppresses Ebola virus replication. J Virol. 2013;87:13795-802.

116. Lee JY, Vinayagamoorthy N, Han K, Kwok SK, Ju JH, Park KS, et al. Association of polymorphisms of cytochrome P450 2D6 with blood hydroxychloroquine levelsin patients with systemic lupus erythematosus. Arthritis Rheumatol. 2016;68:184-90.

117. Horby P, Lim WS, Emberson JR, Mafham M, Bell JL, Linsell L, et al. Dexamethasone in hospitalized patients with covid-19preliminary report. $N$ Engl J Med. 2020. https://doi.org/10.1056/ NEJMoa2021436.

118. Vallelian F, Schaer CA, Kaempfer T, Gehrig P, Duerst E, Schoedon $\mathrm{G}$, et al. Glucocorticoid treatment skews human monocyte di_erentiation into a hemoglobin-clearance phenotype with enhanced heme-iron recycling and antioxidant capacity. Blood. 2010;116:5347-56.

119. Funes SC, Rios M, Fernández-Fierro A, Covián C, Bueno SM, Riedel CA, et al. Naturally Derived Heme-Oxygenase 1 inducers and their therapeutic application to immune-mediated diseases. Front Immunol 2020;11:1467. https://doi.org/10.3389/fimmu.2020.01467.

120. Gemmati D, Tisato V. Genetic hypothesis and pharmacogenetics side of renin-angiotensin-system in COVID-19. Genes (Basel). 2020;11:E1044. https://doi.org/10.3390/genes11091044.

121. Flaten HK, Monte AA. The pharmacogenomic and metabolomic predictors of ACE inhibitor and angiotensin II receptor blocker effectiveness and safety. Cardiovasc Drugs Ther. 2017;31:471-82.

122. Sriram K, Insel PA. Risks of ACE inhibitor and ARB usage in COVID-19: evaluating the evidence. Clin Pharmacol Ther. 2020;108:236-41.

123. Saiz-Rodríguez M, Belmonte C, Román M, Ochoa D, Jiang-Zheng C, Koller D, et al. Effect of ABCB1 C3435T polymorphism on pharmacokinetics of antipsychotics and antidepressants. Basic Clin Pharm Toxicol. 2018;123:474-85.

124. Mahmoudpour SH, Leusink M, van der Putten L, Terreehorst I, Asselbergs FW, de Boer A, et al. Pharmacogenetics of ACE inhibitor-induced angioedema and cough: a systematic review and meta-analysis. Pharmacogenomics. 2013;14:249-60.

125. Gard PR. Implications of the angiotensin converting enzyme gene insertion/deletion polymorphism in health and disease: a snapshot review. Int J Mol Epidemiol Genet. 2010;1:145-57.

126. Yang YY, Lin HC, Lin MW, Chu CJ, Lee FY, Hou MC, et al. Identification of diuretic non-responders with poor long-term clinical outcomes: a 1-year follow-up of 176 non-azotaemic cirrhotic patients with moderate ascites. Clin Sci (Lond). 2011;121:509-21. https://doi.org/10.1042/CS20110018.

127. Ketkar H, Yang L, Wormser GP, Wang P. Lack of efficacy of ivermectin for prevention of a lethal Zika virus infection in a murine system. Diagnostic Microbiol Infect Dis. 2019;95:38-40.

128. Alvinerie M, Dupuy J, Kiki-Mvouaka S, Sutra JF, Lespine A. Ketoconazole increases the plasma levels of ivermectin in sheep. Vet Parasitol. 2008;157:117-22. 